\title{
Characteristics measured by the Eating Disorder Inventory for children at risk and protective factors for disordered eating in adolescent girls
}

This article was published in the following Dove Press journal:

International Journal of Women's Health

27 October 2010

Number of times this article has been viewed

\author{
Sanna Aila Gustafsson' \\ Birgitta Edlund ${ }^{2}$ \\ Lars Kjellin ${ }^{3}$ \\ Claes Norring ${ }^{4}$ \\ 'Psychiatric Research Centre, School \\ of Health and Medical Sciences, \\ University of Örebro; ${ }^{2}$ Department \\ of Public Health and Caring Sciences, \\ University of Uppsala; ${ }^{3}$ Psychiatric \\ Research Centre, University of \\ Örebro; ${ }^{4}$ Centre for Psychiatry \\ Research, Karolinska Institutet, \\ Stockholm, Sweden
}

Objective: The aim of this study was to examine longitudinally the role of characteristics measured by the Eating Disorder Inventory-Child version (EDI-C) to find early predictors that might constitute risk and protective factors in the development of disordered eating.

Method: Participants were divided into three groups based on eating attitudes at T2: disordered eating $(n=49)$, intermediate eating concern $(n=260)$, and healthy eating attitudes $(n=120)$. EDI-C from T1 (four to five years earlier) was then analyzed to find predictors of group classification at $\mathrm{T} 2$.

Results: Drive for thinness and body dissatisfaction emerged as risk factors at T1, while drive for thinness, body dissatisfaction, and interoceptive awareness emerged as protective factors after controlling for initial eating concerns and body mass index.

Discussion: Eating disorders should not be seen as a result of a premorbid personality type. Rather we should take a more social-psychological perspective to explain how individual and sociocultural factors work together in the development of these conditions.

Keywords: eating disorders, EDI-C, risk factors, protective factors

\section{Introduction}

Eating disorders and subclinical problems related to eating, weight, and shape, are conditions that seriously affect psychologic health for a large number of adolescent girls and young women. The Eating Disorder Inventory (EDI) $)^{1,2}$ and its revisions, EDI- $2^{3}$ and EDI- $3,{ }^{4}$ measure characteristics that have been found to be elevated in eating disordered populations. The child version (EDI-C) $)^{5}$ is based on the EDI-2. The same items are used, but the wording of some items has been changed and statements are framed to suit children and adolescents. The EDI-C has shown psychometric properties that are comparable with those of the EDI-2. In an adolescent eating-disordered sample, all subscales, except maturity fears, were elevated compared with healthy controls. ${ }^{6}$

In order to design targeted programs for high-risk individuals, it has been argued that it is important to identify specific risk and protective factors for the development of disturbed eating. ${ }^{7}$ Body dissatisfaction ${ }^{8}$ is a well established risk factor for eating disorders, and several of the other traits measured by EDI-C (ie, perfectionism, drive for thinness, poor interoceptive awareness, ineffectiveness, and interpersonal distrust) have been proposed as predisposing personality factors for the development of eating disorders, ${ }^{9}$ although results are contradictory. ${ }^{9,10}$

It has been suggested that the increasing interest in causal factors in the development of eating disorders has resulted in an overemphasis on risk factors, ${ }^{11}$ because features such as perfectionism, need for control, and self-evaluation concerns have been 
relabeled as risk factors, and are no longer considered central symptoms of the eating disorder. In addition, it has been argued that instead of viewing eating disorders as the result of certain premorbid personality traits, we need to understand how intrapersonal and contextual factors work together and acknowledge that, for many young women in today's society, disordered eating may be an adaptive response to the demands placed on contemporary women. ${ }^{12,13}$

Very little is known about factors that protect against development of an eating disorder development. High self-esteem and an accepting attitude towards body size have been suggested as protective factors, ${ }^{14}$ although the findings need to be replicated in longitudinal studies. In a previous study, it was found that healthy eating attitudes, an accepting attitude towards body size, and positive self-evaluation, particularly with regard to physical and psychologic characteristics, protected against the development of disordered eating. ${ }^{15}$ The present study is conducted with the same participants, at the same two measurement points, in order to study the additional psychologic factors associated with eating disorders and measured by the EDI-C.

The EDI and the EDI-C are widely used instruments to study psychologic factors associated with eating disorders, and the EDI-2 has been shown to discriminate well between eating-disordered subjects, and both psychiatric and normal controls. ${ }^{16}$ However, to our knowledge, no study has used a longitudinal design with a long follow-up period. Therefore, we believe that it is of importance to establish to what extent the EDI-C captures predisposing factors which distinguish girls at risk for developing eating disorders.

Thus, the aim of the present study was to examine longitudinally the role of characteristics measured by the EDI-C to find early predictors that might constitute risk and protective factors in the development of disordered eating.

\section{Methods}

The study sample consisted of girls who took part in a prospective longitudinal study of risk and protective factors related to the development of eating disturbances. The sample was achieved using stratified random sampling from all school classes of a medium-sized Swedish County. The design and methods of the study have been described previously. ${ }^{15}$ The Research Ethics Committee at the Faculty of Medicine, Uppsala University, approved the project.

\section{Instruments}

\section{Children's Eating Attitude Test}

The Children's Eating Attitude Test (ChEAT), ${ }^{16}$ Swedish version, ${ }^{18}$ consists of 26 items, but items 13, 19, and 25 have been reported to have low item-total correlations ${ }^{19}$ and were excluded, resulting in a 23 -item instrument. Scores above 20 on the ChEAT have been suggested to be a cutoff for developing clinical eating disorders, but because we excluded three items, we used a cutoff score of $\geq 16$ (90th percentile) to distinguish the disordered eating (DE) group (see below) in the present study.

\section{Eating Disorder Inventory for Children}

The EDI-C, ${ }^{5}$ Swedish version, ${ }^{20}$ includes 91 items making up 11 subscales, ie, body dissatisfaction, bulimia, drive for thinness, ineffectiveness, perfectionism, interpersonal distrust, interoceptive awareness, maturity fears, ascetism, impulse regulation, and social insecurity. Responses are given on a six-point scale, ranging from "never" to "always", with the most dysfunctional response being ranked 3 , followed by 2 and then 1 , and the three most functional responses are not coded.

\section{Demographic and dieting questionnaire}

A Swedish questionnaire ${ }^{18}$ was employed. The questionnaire contains questions concerning the occurrence of eating disorder symptoms (ie, losing control over eating, vomiting in order to control weight, repeated attempts to eat less than $500 \mathrm{kcal}$ a day, excessive exercise, taking diet pills, diuretics, or laxatives during the last year), and self-reported weight and height that were used to calculate body mass index (BMI, in $\mathrm{kg} / \mathrm{m}^{2}$ ). Because normal weight ranges differ according to age, age-adjusted BMI percentiles were used. ${ }^{21}$

\section{Participants and procedure}

Participants who had completed data collection at T2 and at a previous time point four to five years earlier (T1) were included in the study. Data from T2 were used to divide our study sample into three groups based on eating concerns:

\section{Disordered eating group}

Participants who scored $\geq 16$ on the shortened ChEAT at T2 were defined as the DE group $(n=49)$. All participants in the DE group reported at least one of the following eating disorder symptoms during the previous year: losing control over eating, vomiting in order to control weight, preoccupation with thoughts about eating and weight, repeated attempts to eat less than $500 \mathrm{kcal}$ a day, excessive exercise, and taking diet pills, diuretics, or laxatives.

\section{Intermediate eating group}

Participants with ChEAT scores of $1-15$ at T2 were defined as the intermediate eating (IE) group $(n=260)$. 


\section{Healthy eating attitudes}

Participants with ChEAT scores $=0$ were defined as the healthy eating $(\mathrm{HE})$ group at T2 $(\mathrm{n}=120)$.

EDI-C data from T1 were then analyzed to find predictors that might constitute risk and protective factors in the development of disordered eating. Because we were interested in studying predictors for developing disordered eating during the follow-up period, all participants with ChEAT scores $\geq 16$ at $\mathrm{T} 1$ were excluded from the study. The mean age of the participants at T1 was 13.6 (range 12-16) years, with no significant age difference between the three groups. At T2, the mean age was 18.1 (range 16-21) years.

\section{Statistics}

The three groups were compared by analysis of variance (ANOVA) on each EDI-C subscale. In the next step, we conducted analyses of covariance (ANCOVAs) on each subscale, with ChEAT scores at T1 entered as a covariate. Higher BMI has been associated with body dissatisfaction, unhealthy attitudes to eating and weight, and negative self-evaluation. ${ }^{18,22}$ Therefore, a two-way ANOVA (group $\times$ BMI) was finally carried out on each EDI-C subscale. BMI was entered as a dichotomous fixed factor with a breakpoint at the 75th ageadjusted BMI percentile. ${ }^{19} \mathrm{~A}$ variable was considered to be a risk factor if the DE group differed significantly from both other groups. Correspondingly, a variable was considered to be a protective factor if the HE group differed significantly from both other groups. Bonferroni's correction for multiple tests was used to reduce the risk of Type I errors, resulting in an alpha level of $P=0.0045$.

\section{Results}

The mean BMI for the total group was 19.6 (range 13.6-32.0). The HE group had a lower BMI (18.7) compared with both other groups (20.0 for the DE group and 19.9 for the IE group), although this difference was not significant due to the conservative alpha value of this study. ChEAT scores at $\mathrm{T} 1$ differed between all three groups, with the lowest mean score in the HE group (1.2), followed by the IE group (3.2), and with the DE group reporting the highest ChEAT scores $(5.6, P<0.001)$. These results have been reported in a previous study. ${ }^{15}$

Seven of the variables did not differ significantly between any of the groups (see Table 1). Drive for thinness and body dissatisfaction differed significantly between all three groups, with the DE group reporting the highest values. The HE group reported significantly lower scores on interoceptive awareness and impulse regulation compared with both other groups. However, impulse regulation did not remain significant after controlling for initial ChEAT scores. Variables that did not show significant differences after controlling for initial ChEAT scores were dropped from further analyses. In the next step, two-way ANOVAS to control for BMI were conducted for drive for thinness, body dissatisfaction, and interoceptive awareness. All three variables still remained significant after controlling for BMI (drive for thinness: $\mathrm{F}=24.3, P<0.001$; body dissatisfaction: $\mathrm{F}=13.8, P<0.001$; interoceptive awareness: $\mathrm{F}=10.6$, $P<0.001)$ with the same group differences as in the oneway ANOVAs.

Consequently, drive for thinness, body dissatisfaction, and interoceptive awareness emerged as protective factors and drive for thinness and body dissatisfaction as risk factors after controlling for initial ChEAT scores and BMI.

\section{Discussion}

The aim of the present study was to examine the role of characteristics measured by the EDI-C longitudinally to find early predictors that might constitute risk and protective factors in the development of disordered eating. Drive for thinness and body dissatisfaction emerged as both risk and protective factors for the development of disordered eating four to five years later. Thus, an accepting attitude towards body size in early adolescence seems to be a protective factor in a similar fashion as dissatisfaction with body size and drive for thinness are associated with increased risk of developing eating disorders.

Eating disorders have been described as a result of a compliant, perfectionistic, and dependent personality type, ${ }^{23}$ and these thoughts are still influential in the field of eating disorder research. Metareviews ${ }^{8-10}$ has not found convincing evidence that perfectionistic and dependent personality traits are predisposing factors for eating disorders. In keeping with previous research, the present study does not support the presence of a premorbid personality that sets the stage for disordered eating. Rather, drive for thinness and body dissatisfaction seem to precede elevated scores in these psychologic factors. The results of the present study add to previous research,,$^{24,11,13}$ and suggest that, rather than seeing eating disorders as a result of a premorbid personality type, we should take a more sociopsychologic perspective to explain how an initial negative body image and drive for thinness is extended such that it leads to these psychologic problems.

In addition to low scores on the drive for thinness and body dissatisfaction subscales, interoceptive awareness was also protective against developing disordered eating four to five years later. Thus, protective factors may not always be 
Table I Mean values (standard deviation) and comparisons with one-way ANOVAs for the three groups on the EDI-C subscales at TI

\begin{tabular}{|c|c|c|c|c|c|}
\hline Subscale & DE group & IE group & HE group & $\begin{array}{l}\text { F value ( } P \text { value) } \\
\text { one-way ANOVA }\end{array}$ & $\begin{array}{l}\text { Post hoc } \\
\text { one-way ANOVA }\end{array}$ \\
\hline DT & $5.3(5.2)$ & $2.1(3.3)$ & $0.7(2.2)$ & $32.4(<0.00 \mathrm{I})^{\prime}$ & $\mathrm{HE}<\mathrm{IE}<\mathrm{DE}$ \\
\hline B & $0.8(2.2)$ & $0.5(1.2)$ & $0.2(0.6)$ & $5.2(0.006)$ & NS \\
\hline $\mathrm{BD}$ & II.5 (7.3) & $8.5(6.4)$ & $4.7(4.7)$ & $27.2(<0.00 \mathrm{I})^{2}$ & $\mathrm{HE}<\mathrm{IE}<\mathrm{DE}$ \\
\hline I & $4.5(4.3)$ & $3.8(4.1)$ & $2.6(3.7)$ & $4.9(0.008)$ & NS \\
\hline$P$ & $0.8(1.4)$ & $0.7(1.3)$ & $0.4(1.1)$ & $3.8(0.022)$ & NS \\
\hline ID & $3.3(3.7)$ & $3.4(3.1)$ & $2.7(2.5)$ & $2.2(0.116)$ & NS \\
\hline IA & $3.6(3.2)$ & $2.6(2.8)$ & $1.3(1.9)$ & $16.2(<0.001)^{3}$ & $\mathrm{HE}<\mathrm{IE}=\mathrm{DE}$ \\
\hline MF & $5.7(3.9)$ & $5.4(3.5)$ & $5.7(2.9)$ & $0.6(0.55 \mathrm{I})$ & NS \\
\hline$A$ & $4.7(2.9)$ & $4.3(2.7)$ & $4.3(3.1)$ & $0.4(0.423)$ & NS \\
\hline IR & $3.9(3.6)$ & $3.1(3.6)$ & $1.9(2.6)$ & $8.4(<0.000 \mathrm{I})^{4}$ & $\mathrm{HE}<\mathrm{IE}=\mathrm{DE}$ \\
\hline SI & $4.5(2.9)$ & $4.1(2.5)$ & $3.3(2.2)$ & $6.2(0.116)$ & NS \\
\hline
\end{tabular}

Notes: Results of ANCOVAs controlling for initial ChEAT scores: 'Still significant, $\mathrm{F}=1 \mathrm{I} .6, \mathrm{P} \leq 0.00 \mathrm{I} ;{ }^{2}$ still significant, $\mathrm{F}=9.4, P \leq 0.00 \mathrm{I} ;{ }^{3}$ still significant, $\mathrm{F}=5.8, P=0.003$; ${ }^{4} \mathrm{NS}, \mathrm{F}=2.7, P=0.072$.

Abbreviations: EDI-C, Eating Disorder Inventory-Child version; BD, body dissatisfaction; B, bulimia; DT, drive for thinness; I, ineffectiveness; P, perfectionism; ID, interpersonal distrust; IA, interoceptive awareness; MF, maturity fears; A, ascetism; IR, impulse regulation; SI, social insecurity; ANOVA, analysis of variance; ANCOVAs, analyses of covariance; ChEAT, Children's Eating Attitude Test; HE, healthy eating; IE, intermediate eating; DE, disordered eating; NS, not significant.

the opposite of a risk factor. Interoceptive awareness reflects one's ability to correctly identify different emotions and bodily sensations. ${ }^{25}$ Previous research has shown that difficulty in identifying and describing feelings is associated with disordered eating attitudes. ${ }^{26}$ Thus, although girls who developed disordered eating later did not differ from girls who developed intermediate eating concerns later, in regard to interoceptive awareness, girls in the HE group were found to be already more aware of interoceptive signals four to five years previously. It may be hypothesized that an ability to identify and express one's feelings correctly might help to find strategies to deal with the real issue instead of adopting the view that thinness will lead to happiness and success.

In conclusion, girls who developed disordered eating did not differ from their peers with regard to psychologic features that had been associated with eating disorders four to five years earlier. However, they expressed more body dissatisfaction and drive for thinness. Thus, instead of viewing eating disorders as a result of certain premorbid personality traits, we should focus on understanding how individual and contextual factors work together in the development of eating disorders. Girls with particularly healthy attitudes to eating, shape, and weight at $\mathrm{T} 2$ were also already more attentive to interoceptive signals four to five years earlier. Thus, we suggest that, in addition to confronting the societal ideals for female beauty, prevention interventions should also focus on teaching adolescent girls to identify and express their thoughts and feelings.

A limitation of the present study is the rather small number of subjects in the DE group. It is difficult and costly to perform prospective longitudinal studies, and dropout rates become higher the longer the follow-up period..$^{9}$ It is possible that some variables failed to show significant differences due to small numbers and a conservative alpha value. However, the prospective design, the long follow-up period, and the representative sample are strengths of the study.

\section{Disclosure}

The authors report no conflicts of interest in this work.

\section{References}

1. Garner DM, Olmsted MP. The Eating Disorders Inventory Manual. Odessa, FL: Psychological Assessment Resources; 1983.

2. Garner DM, Olmstedt MP, Polivy J. Development and validation of a multidimensional Eating Disorder Inventory for anorexia and bulimia. Int J Eat Disord. 1983;2(2):15-34.

3. Garner DM. Eating Disorder Inventory-2. Professional Manual. Odessa, FL: Psychological Assessment Resources; 1991a.

4. Garner DM. Eating Disorder Inventory-3. Odessa, FL: Psychological Assessment Resources; 2004.

5. Garner DM. The Eating Disorder Inventory-C. Lutz, FL: Psychological Assessment Resources; 1991b.

6. Thurfjell B, Edlund B, Arinell H, Hägglof B, Engström I. Psychometric properties of Eating Disorder Inventory for children (EDI-C) in Swedish girls with and without a known eating disorder. Eat Weight Disord. 2003;8(4):296-303.

7. Stice E, Ng J, Shaw H. Risk factors and prodromal eating pathology. J Child Psychol Psychiatry. 2010;51(4):518-523.

8. Stice E. Risk and maintenance factors for eating pathology: A metaanalytic review. Psychol Bull. 2002;128(5):825-848.

9. Lilenfeld LR, Wonderlich S, Riso LP, Crosby R, Mitchell J. Eating disorders and personality: A methodological and empirical review. Clin Psychol Rev. 2006;26(3):299-320.

10. Jacobi C, Hayward C, de Zwaan M, Kraeme HC, Agras W. Coming to terms with risk factors for eating disorders: Application of risk terminology and suggestions for a general taxonomy. Psychol Bull. 2004;130(1):19-65.

11. Polivy J, Herman C. Distinguishing risk factors from symptoms: Are eating disorders simply disordered eating? In: Salzinger K, Serper MR, editors. Behavioral Mechanisms and Psychopathology: Advancing the Explanation of its Nature and Treatment. Washington, DC: American Psychological Association. 2009. 
12. Gremillion H. Complexities of power and meaning: A reflection on Parts IV and V. In: Malson H, Burns M, editors. Critical Feminist Approaches to Eating Disorders. New York, NY: Routledge/Taylor and Francis Group; 2009.

13. Hesse-Biber S, Leavy P, Quinn CE, Zoino J. The mass marketing of disordered eating and eating disorders: The social psychology of women, thinness and culture. Womens Stud Int Forum. 2006;29(2):208-224.

14. Crago M, Shisslak CM, Ruble A. Protective factors in the development of eating disorders. In: Striegel-Moore RH, Smolak L, editors. Eating Disorders: Innovative Directions in Research and Practice. Washington, DC: American Psychological Association; 2001.

15. Gustafsson SA, Edlund B, Kjellin L, Norring C. Risk and protective factors for disturbed eating in adolescent girls - aspects of perfectionism and attitudes to eating and weight. Eur Eat Disord Rev. 2009; 17(5):380-389.

16. Nevonen L, Clinton D, Norring C. Validating the EDI-2 in three Swedish female samples: Eating disorder patients, psychiatric outpatients and normal controls. Nord J Psychiatry. 2006;60(1):44-50.

17. Maloney MJ, McGuire J, Daniels SR, Specker B. Dieting behavior and eating attitudes in children. Pediatrics. 1989;84(3):482-489.

18. Edlund B, Hallqvist G, Sjöden PO. Attitudes to food, eating and dieting behaviour in 11 and 14-year-old Swedish children. Acta Paediatr. 1994;83(6):572-575.
19. Smolak L, Levine MP. Psychometric properties of the Children's Eating Attitudes Test. Int J Eat Disord. 1994;16(3):275-282.

20. Thurfjell B, Edlund B, Arinell H, Hagglof B, Garner DM, Engstrom I. Eating Disorder Inventory for Children (EDI-C): Effects of age and gender in a Swedish sample. Eur Eat Disord Rev. 2004;12(4): 256-264.

21. He Q, Albertsson-Wikland K, Karlberg J. Population-based body mass index reference values from Goteborg, Sweden: Birth to 18 years of age. Acta Paediatr. 2000;89(5):582-592.

22. Edlund B, Halvarsson K, Gebre-Medhin M, Sjöden PO. Psychological correlates of dieting in Swedish adolescents: A cross-sectional study. Eur Eat Disord Rev. 1999;7(1):47-61.

23. Bruch H. Eating disorders: Obesity, anorexia, and the persona within. New York, NY: Basic Books; 1973.

24. McFarlane T, McCabe RE, Jarry J, Olmsted MP, Polivy J. Weightrelated and shape-related self-evaluation in eating-disordered and noneating-disordered women. Int J Eat Disord. 2001;29(3):328-335.

25. Taylor GJ, Bagby RM, Parker JD. The alexitymia construct. A potential paradigm for psychosomatic medicine. Psychosomatics. 1991;32(2):153-164.

26. de Beradis D, Carano A, Gambi F, et al. Alexitymia and its relationship with body checking and body image in a nonclinical female sample. Eat Behav. 2007;8(3):296-304.
International Journal of Women's Health

\section{Publish your work in this journal}

The International Journal of Women's Health is an international, peerreviewed open-access journal publishing original research, reports, reviews and commentaries on all aspects of women's healthcare including gynecology, obstetrics, and breast cancer. Subject areas include: Chronic conditions (migraine headaches, arthritis, osteoporosis);

\section{Dovepress}

Endocrine and autoimmune syndromes; Sexual and reproductive health; Psychological and psychosocial conditions. The manuscript management system is completely online and includes a very quick and fair peer-review system. Visit http://www.dovepress.com/ testimonials.php to read real quotes from published authors. 